\title{
Adverse health outcomes among workers of wood pellet production facilities
}

\author{
Rafał L. Górnyy ${ }^{1, A-F}{ }^{\oplus}$, Małgorzata Gołofit-Szymczak ${ }^{1, B-E \oplus}$ \\ ${ }^{1}$ Central Institute for Labour Protection / National Research Institute (CIOP-PIB), Warsaw, Poland \\ A - Research concept and design, B - Collection and/or assembly of data, C - Data analysis and interpretation, \\ $D$ - Writing the article, $E$ - Critical revision of the article, F - Final approval of article
}

Górny RL, Gołofit-Szymczak M. Adverse health outcomes among workers of wood pellet production facilities. Ann Agric Environ Med. 2020; 27(1): 154-159. DOI: 10.26444/aaem/115178

\begin{abstract}
I Abstract
Introduction. Workers of pellet production facilities (WPPF) are exposed to high concentrations of wood dust and microbial pollutants. Such stimulation may lead to numerous allergic and toxic reactions, infections, and other non-specific syndromes. Objective. To check the influence of individual traits of workers and characteristic features / factors of their living and working environments on the probability of adverse outcomes' appearance.

Materials and Method. The questionnaire study assessing adverse health effects resulting from individual exposure was conducted among 28 workers of 10 Polish WPPF. The logistic regression (for dichotomous variables) was used to determine the appearance probability (given as odds ratio) of adverse symptoms or diseases.

Results and Conclusions. WPPF workers may have an increased risk of developing work-related adverse health outcomes. Both the individual traits and environmental exposure factors significantly influence the probability of their occurrence.
\end{abstract}

\section{Key words}

pellet, wood dust, bioaerosol, health questionnaire, occupational exposure, individual traits, environmental factors, logistic regression

\section{INTRODUCTION}

The wood industry employs about 3.6 million workers in Europe. In Poland, the percentage of workers exposed to wood dust levels above $5 \mathrm{mg} / \mathrm{m}^{3}$ is almost the same (14\%) as in the European Union $(16 \%)[1,2]$. Wood dust is a known human carcinogen assigned to group 1 [3]. Acute and chronic exposures may lead to sensitization and irritation of the respiratory tract and skin. Both respiratory functional changes and occupational asthma have already been observed among workers at wood dust concentrations below $1 \mathrm{mg} / \mathrm{m}^{3}[4,5]$. Occupational exposures to wood dust are not solely limited to wood particulates but include also a microbial fraction, i.e. microorganisms and substances derived from them. Such microbial stimulation may be responsible for allergic and toxic reactions, infections, and other non-specific syndromes.

Pellet production is still a relatively new branch of the wood industry; however, global trade and use of wood pellets as an ecological fuel or hygienic bedding for farm and domestic animals have been constantly growing in the $21^{\text {st }}$ century. The very few studies conducted so far in wood pellet production facilities (WPPF) have revealed that wood dust, microorganism, endotoxin and $(1 \rightarrow 3)-\beta$-D-glucan concentrations periodically reach extremely high values up to $65 \mathrm{mg} / \mathrm{m}^{3}, 19320 \mathrm{CFU} / \mathrm{m}^{3}, 215 \mathrm{ng} / \mathrm{m}^{3}$ and $1525 \mathrm{ng} / \mathrm{m}^{3}$, respectively $[6,7]$. All these contaminants, together with individual workers' traits and the characteristic features / factors of their living and working environments may influence the frequency of adverse health outcomes. Hence, the aim of this study was to check the above using the logistic regression analysis of data collected with epidemiological questionnaire.

Address for correspondence: Rafał L. Górny Central Institute for Labour Protection - National Research Institute (CIOP-PIB), Poland

E-mail: ragor@ciop.pl

Received: 13.11.2019; accepted: 09.12.2019; first published: 19.12.2019

\section{MATERIALS AND METHOD}

The questionnaire study, assessing adverse health effects resulting from individual exposure, was conducted among 28 workers of 10 Polish WPPF. The full characteristics of surveyed workplaces are presented in a recently published paper by Górny et al. [7]. The questionnaire analyzed the subjective feelings of employees related to work in exposure to wood dust and microbiological agents, as well as objective facts about their medically confirmed health status. The study used a standard epidemiological questionnaire, developed using international models of this type of research (i.e. European Community Respiratory Health Survey and American Thoracic Society questionnaires).

In order to quantitatively characterize the group of WPPF employees, the actual numbers of people/cases were used or arithmetic means with standard deviations (SD) calculated. In the analysis of dichotomous questionnaire variables, logistic regression was used to determine the probability (described as odds ratio, OR, and 95\% confidence interval, CI) of the appearance of adverse health symptoms or diseases under the influence of individual workers' traits, living and working environment conditions. All these analyses were carried out using the STATISTICA data analysis software system” version 10. (StatSoft, Inc., Tulsa, OK, USA).

\section{RESULTS AND DISCUSSION}

Men dominated among the WPPF employees (Tab. 1). Because there was only one woman in the group of 28 people, in further analyzes the gender factor was omitted and the whole group treated as 'homogeneous in this respect'. The studied workers were dominated by young employees (75\%) with 10 years of work experience. Among them, 25\% had already worked in woodworking factories. All workers 
possessed personal protective equipment when carrying out activities at workplaces: filtering half-masks, goggles and work gloves were used by $88 \%, 50 \%$ and $50 \%$, respectively. Employees also had the opportunity to wash their work clothes and take a shower after each shift. The percentages of current and former smokers among employees were 38\% and $25 \%$, respectively.

Analysis of adverse health effects among employees revealed, among others:

a) flu-like symptoms, most often experienced fatigue (88\%), sweating without physical exertion (63\%), and joint and muscle pains (50\%);

b) respiratory symptoms, $25 \%$ had dry cough and wheezing, $13 \%$ cough with phlegm;

c) irritations, $13 \%$ had a runny nose, throat and skin irritations, $38 \%$ had nose and eye irritations;

d) neurological symptoms, 38\% complained of headaches and $13 \%$ of concentration difficulties during work shift;

e) alimentary tract symptoms, $25 \%$ complained of heartburn and diarrhea.

According to $25 \%$ of employees, the above-mentioned adverse effects were work-related.

On investigating the environmental factors influencing the health status of employees, it was found that: $38 \%$ of them grew up and currently live on a farm, in which $13 \%$ of them had contact with dairy farming, 25\% with cereal cultivation, and $13 \%$ with pomiculture and poultry farming. The impact of place of residence and type of building, its construction materials, presence of indoor moisture traces, mould stains and pets were also examined. Analysis revealed that:

a) $50 \%, 37 \%$ and $13 \%$ of employees live in the countryside, in small towns (i.e. up to 50,000 inhabitants) and in large cities (i.e. more than 50,000 inhabitants), respectively;

b) $37 \%$ of employees currently live in a block of flats and $63 \%$ in detached houses;

c) $50 \%, 37 \%$ and $13 \%$ of employees live in buildings constructed of concrete, brick or other material (excluding wood), respectively;

d) $13 \%$ of employees found moisture traces and / or mould stains on construction or finishing elements in their premises;

e) among the employees, $38 \%$ had a cat at home, $50 \%$ a dog, and $13 \%$ a rodent.

Application of logistic regression in the analysis of dichotomous questionnaire data allowed the selection of factors having real and most significant impact on the adverse health effects identified by employees (Tab. 2). The analysis revealed the following:

a) wood dust concentrations exceeding the permissible level (i.e. $3 \mathrm{mg} / \mathrm{m}^{3}$ ) which significantly determined the probability of fatigue, joint and muscle pains, nose and eye irritations, headache, heartburn and diarrhea occurrence among employees;

b) a high probability of fatigue, joint and muscle pains, nose and eye irritations, headache and allergy to common environmental allergens was also significantly associated with exposure to bioaerosol concentrations exceeding $2000 \mathrm{CFU} / \mathrm{m}^{3}$;

c) despite the fact that pellet plant workers were mostly young people, the probability of the appearance of studied irritations, mostly of the neurological, flu-like and other respiratory as well as alimentary tract symptoms, was also high;

d)former employment in the facilities of the same branch resulted in a higher probability of the appearance of chills, wheezing, nose, eye and skin irritations, headache, concentration difficulties, heartburn, and diarrhea;

e) the use of personal protective equipment (especially masks and goggles) to a large extent protected against the development of adverse effects; however, when wood dust concentrations were very high, the appearance of allergy to common environmental allergens, fever, chills, cough with phlegm, irritations, headache, concentration difficulties, heartburn, fatigue, and sweating without physical effort, was very probable;

f) smoking combined with exposure to high wood dust levels resulted in an increased probability of nose, throat and eye irritations, wheezing and gastrointestinal complaints, sweating, joint and muscle pains or chills;

g) in agreement with the so-called hygienic theory, growing up on a farm protects (to some extent) against adverse effects provoked by environmental factors in adult life. Analysis of questionnaire data confirmed that with reference to allergies, however, that occupational stimulation by wood dust pollutants may result in a higher probability of wheezing, heartburn and diarrhea, sweating, chills, runny nose, throat and nose irritations;

h)the type of building and the material from which it is constructed had ambiguous importance in revealing adverse health effects. The hygienic quality of the premises (especially moisture traces and / or mould stains) was more important in this respect. Regression analysis showed that poor indoor quality (especially in large city houses) increased the occurrence probability of allergies or flu-like symptoms;

i) the presence of pets was also significant in this context. Cats, dogs and rodents may increase the probability of the appearance of flu-like symptoms, runny nose, throat irritation, and allergies to common environmental allergens.

The results of this study are in a good agreement with the findings of other occupational exposure investigations. Wiggans et al. [8] found that wood dust exposure resulted among workers an increased occurrence probability of dry cough $(\mathrm{OR}=1.2-5.5)$, cough with phlegm $(\mathrm{OR}=0.9-20)$, wheezing $(\mathrm{OR}=1.3-5.9)$, nose irritations $(\mathrm{OR}=0.8-16.4)$, and eye and throat irritations $(\mathrm{OR}=1-13.5)$. Douwes et al. $[9,10]$, studying workers' exposure to pine wood dust, observed an increased probability of dry cough (OR: 2.7 (95\% CI=1.2$6.5)$, and nose and eye irritation occurrence (OR: 8 (95\% $\mathrm{CI}=1-62.7)$. Fransman et al. [11], assessing the respiratory symptoms among plywood mill workers, found (inter alia) a higher prevalence of wheezing (OR: 1.2 (95\% CI=0.7-2) compared to the general population. A study by Ahman [12], similar to the presented wood pellet production facility investigations, noted an increased occurrence of adverse outcomes during occupational activities, an improvement in health status during leisure time, and a deterioration of health on the first day after a holiday. 
Table 1. Individual traits as well as characteristic features/factors of living and working environments of workers ( $\mathrm{n}=28$ ) in studied wood pellet production facilities

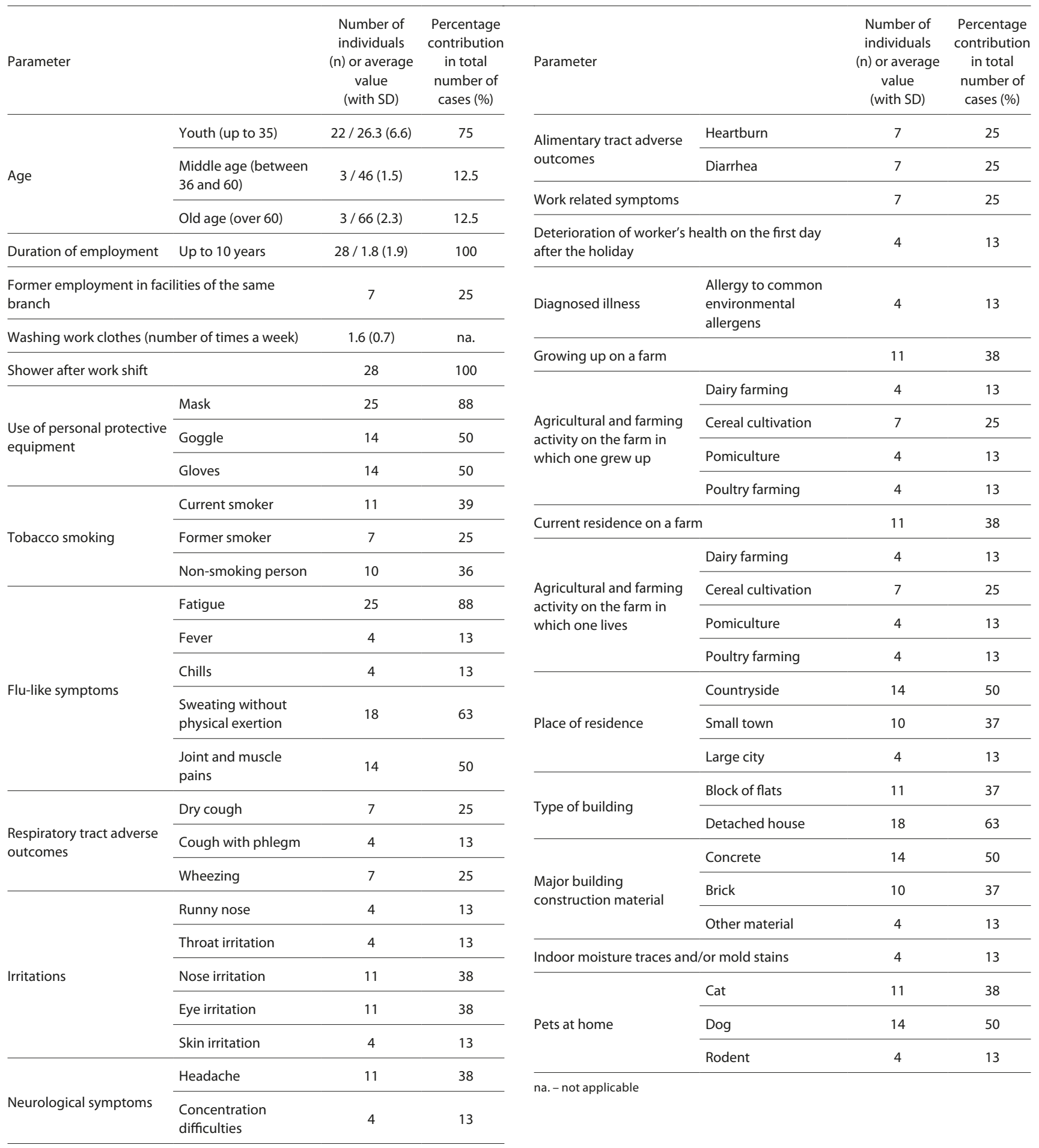

\section{CONCLUSIONS}

Pellet production facility workers exposed to high concentrations of wood dust and bioaerosols, may have an increased risk of developing work-related adverse health outcomes. The individual traits, as well as the characteristic features / factors of both living and occupational environments, significantly influence the probability of the appearance of allergy to common environmental allergens,

respiratory and alimentary tract adverse effects, irritations, as well as flu-like and neurological symptoms.

\section{Acknowledgment}

The study was funded by the Polish Ministry of Science and Higher Education / National Centre for Research and Development in Warsaw within the scope of the fourth stage of the National Programme 'Improvement of safety and working conditions (2017-2019)' through Grant No. II.N.15. 


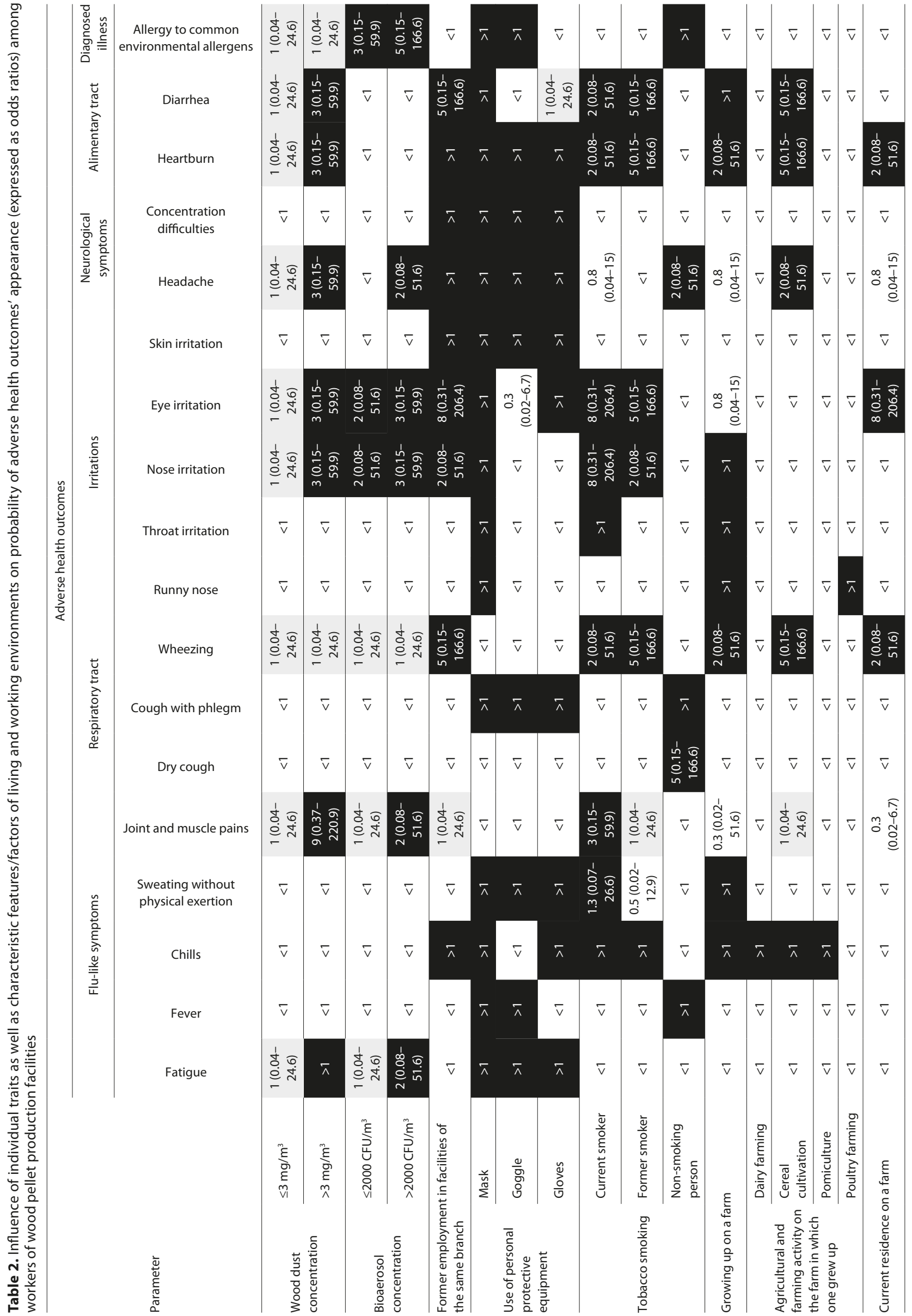




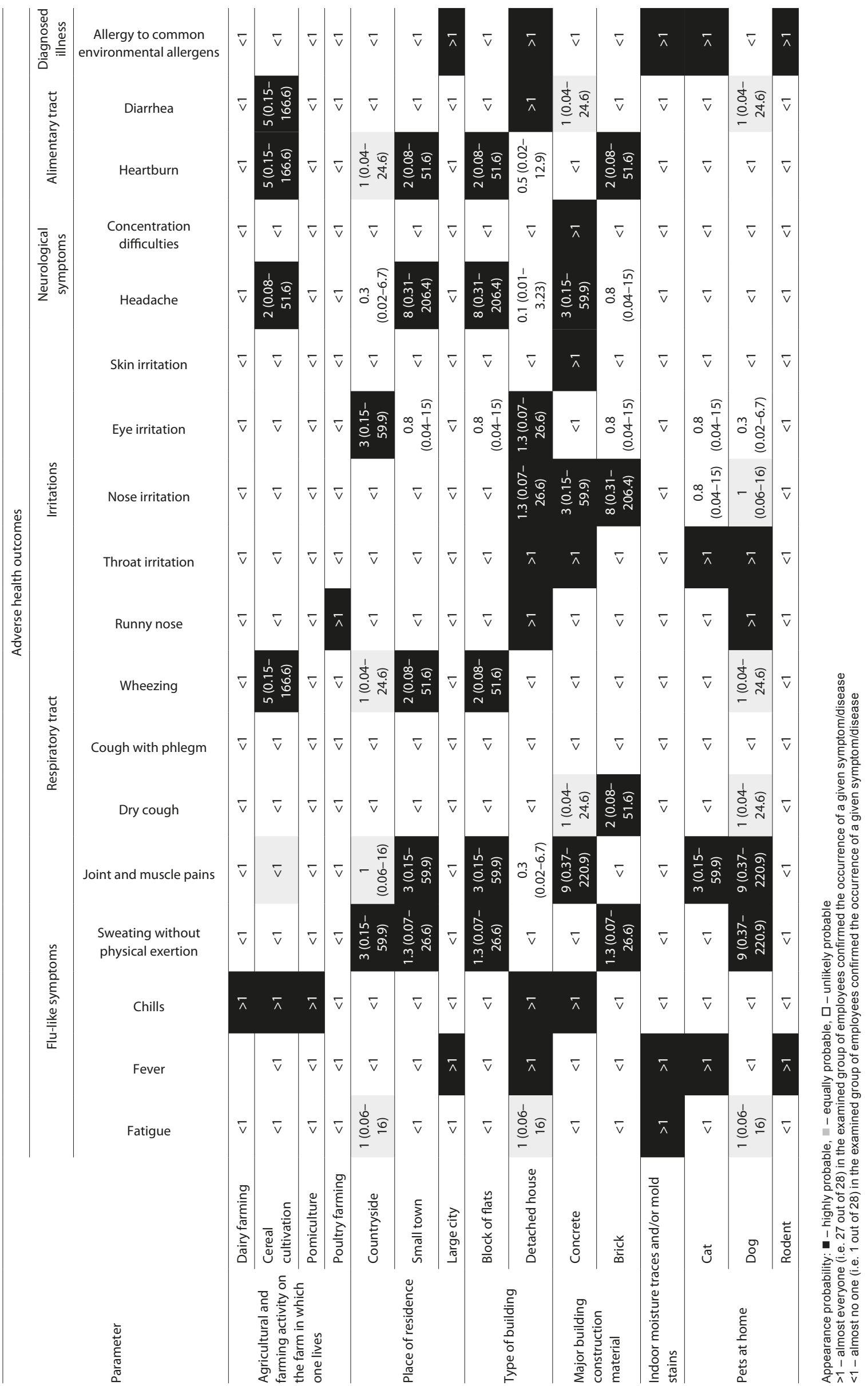




\section{REFERENCES}

1. Kauppinen T, Vincent R, Liukkonen T, Grzebyk M, Kauppinen A Welling I, Arezes P, Black N, Bochmann F, Campelo F, Costa M, Elsigan G, Goerens R, Kikemenis A, Kromhout H, Miguel S, Mirabelli D, McEneany R, Pesch B, Plato N, Schlünssen V, Schulze J, Sonntag R, Verougstraete V, De Vicente MA, WolfJ, Zimmermann M, HusgafvelPursiainen K, Savolainen K. Occupational exposure to inhalable wood dust in the members states of the European Union. Ann Occup Hyg. 2006; 50: 549-561.

2. Statistics Poland. Statistical yearbook of Poland. Statistics Poland, Warsaw 2018.

3. IARC 2012, IARC monographs on the evaluation of carcinogenic risks to humans - Arsenic, metals, fibers, and dusts - volume $100 \mathrm{C}$, International Agency for Research on Cancer, Lyon.

4. NTP - National Toxicology Program 2000, Report on carcinogens Background document for wood dust, U.S. Department of Health and Human Services, Durham.

5. SCOEL 2003, Recommendation from the Scientific Committee on Occupational Exposure Limits: Risk assessment for wood dust, SCOEL/ SUM/102.
6. Callan BE, Leal I, Islam A, Foord B. Analysis of Canadian wood pellets for the presence of living phytopathogenic fungi and pinewood nematode. Bull OEPP. 2018; 48: 245-253.

7. Górny RL, Gołofit-Szymczak M, Cyprowski M, Stobnicka-Kupiec A. Nasal lavage as analytical tool in assessment of exposure to particulate and microbial aerosols in wood pellet production facilities. Sci Total Environ. 2019; 697 (doi.org: 10.1016/j.scitotenv.2019.134018)

8. Wiggans RE, Evans G, Fishwick D, Barber CM. Asthma in furniture and wood processing workers: a systematic review. Occup Med. 2016; 66: 193-201.

9. Douwes J, McLean D, Slater T, Pearce N. Asthma and other respiratory symptoms in New Zealand pine processing sawmill workers. Am J Ind Med. 2001; 39: 608-615.

10. Douwes J, McLean D, van der Maarl E, Heederik D, Pearce N. Worker exposures to airborne dust, endotoxin and beta $(1,3)$-glucan in two New Zealand sawmills. Am J Ind Med. 2000; 38: 426-430.

11. Fransman W, McLean D, Douwes J, Demers PA, Leung V, Pearce N. Respiratory symptoms and occupational exposures in New Zealand plywood mill workers. Ann Occup Hyg. 2003; 47: 287-295.

12. Ahman M. Nasal peak flow rate records in work related nasal blockage. Acta Otolaryngol (Stockh). 1992; 112: 839-844. 